\title{
A Morfologia Derivacional Contribui para a Leitura e Escrita no Português?
}

\author{
Does Derivational Morphology Contribute to Reading and Spelling in Portuguese?
}

\author{
Márcia Maria Peruzzi Elia da Mota*, Luciana Anibal \& Simone Lima \\ Universidade Federal de Juiz de Fora
}

\begin{abstract}
Resumo
Estudos realizados em língua inglesa mostram que a habilidade de refletir sobre os morfemas que compõem as palavras está associada ao sucesso no reconhecimento e compreensão de palavras, na leitura, e na escrita. $\mathrm{O}$ português é uma língua com uma ortografia bem mais transparente em termos das correspondências entre letra e som do que o inglês. Neste estudo investigamos se o processamento da morfologia derivacional contribui para leitura e escrita no português e se essa contribuição é independente da consciência fonológica. Os resultados mostram que a habilidade de refletir sobre os morfemas contribui tanto para leitura quanto para escrita, e que essa contribuição é até certo ponto independente do processamento fonológico.

Palavras-chaves: Consciência metalingüística; consciência morfológica; alfabetização.
\end{abstract}

\begin{abstract}
Studies carried out in English orthography show that the ability to reflect upon the word's morphemes is related to the success in recognizing words, reading comprehension and spelling. Portuguese is a language with a more transparent letter-sound correspondence rule than English. This study investigated whether derivational morphology processing contributes to reading and spelling in Portuguese and whether this contribution is independent of phonological awareness. The results show that the ability to reflect upon the morpheme of the words contributes both to reading and spelling and this contribution is, to a certain extent, independent of phonological processing.

Keywords: Metalinguistic awareness; morphological awareness; literacy.
\end{abstract}

A escrita combina dois tipos de princípios: o princípio fonográfico e o semiográfico. O primeiro envolve estabelecer como unidades gráficas, os grafemas ou letras, correspondem aos sons que compõem a fala, ao nível dos fonemas ou sílabas. O segundo princípio, o semiográfico, envolve estabelecer como os grafemas representam significados (Marec-Breton \& Gombert, 2004). O processamento morfológico está mais fortemente associado ao princípio semiográfico, ao passo que o processamento fonológico está mais fortemente associado ao princípio fonográfico.

Morfemas são as menores unidades lingüísticas que têm significado próprio. As palavras podem ser morfologicamente simples, quando são compostas de um morfema, ou morfologicamente complexas quando elas possuem mais de um morfema. A habilidade de refletir sobre essas unidades de significado é chamada consciência morfológica e pode ajudar o aprendiz a entender o princípio semiográfico (Carlisle, 1995). Isto ocorre, porque a ortografia de muitas palavras depende da sua origem. Palavras como "açucarado", que têm ortografia ambígua, podem ser escritas de forma correta se soubermos sua origem

"Endereço para correspondência: Universidade Federal de Juiz de Fora, Campus Universitário Martelos, Juiz de Fora, MG, 36036-330. Tel.: (32) 3229 3101; Fax: (32) 32293110. E-mail: marcia.mota@ufjf.edu.br "açúcar". Os significados delas podem ser inferidos também na leitura se nós soubermos o significado da palavra que as originou.

Em uma série de estudos que visavam explorar a relação entre a consciência morfológica e a alfabetização em crianças falantes do inglês, Joanne Carlisle mostrou que a habilidade de refletir sobre os morfemas das palavras estava associada ao desempenho na leitura de palavras isoladas e à compreensão de leitura (Carlisle, 1995, 2000; Carlisle \& Fleming, 2003), e também ao desempenho da escrita (Carlisle, 1988, 1996).

Além dos estudos de Carlisle, outras pesquisas realizadas sobre língua inglesa obtiveram resultados semelhantes, tanto no âmbito da leitura (Deacon \& Kirby, 2004; Nagy, Berninger \& Abbot, 2006), como também nas investigações sobre a escrita (Deacon \& Bryant, 2005; Nunes, Bindman \& Bryant, 1997).

Existem duas grandes classes de morfemas, as raízes e os afixos. A raiz pode ser definida como o núcleo mínimo de uma construção morfológica. Os afixos podem ser de dois tipos: prefixos ou sufixos. Os morfemas também podem ser classificados como flexões que, determinam o gênero e número das palavras; e o gênero, número e o tempo dos verbos, e as derivações, que por sua vez, podem ser prefixos (ex., "refazer") ou sufixos (ex., "leiteiro"), e têm a função de formar novas palavras (Laroca, 2005). 
As flexões têm um caráter morfossintático e possuem uma estabilidade semântica, ao passo que as derivações tratam da estrutura das palavras, neste caso pode haver extensões do sentido destas palavras (Laroca, 2005). Morfologia derivacional se refere à formação das palavras a partir de processos que envolvem as derivações. Morfologia flexional se refere aos processos de formação de palavras que envolvem as flexões.

Existe alguma evidência de que as crianças reagem diferentemente à morfologia derivacional e a flexional. Deacon e Bryant (2005) deram a crianças de cinco a oito anos de idade um teste, no qual as crianças tinham que escrever palavras com um morfema e palavras com dois morfemas. Metade das palavras de dois morfemas era de palavras derivadas e a outra metade eram palavras flexionadas. As palavras tinham o mesmo som final. Os resultados deste estudo mostraram que as crianças escreviam corretamente os sons finais das palavras mais vezes quando eram morfemas do que quando não eram, mas a análise do tipo de morfema escrito mostrou que este resultado era verdadeiro apenas para as flexões.

Os autores concluíram que a diferença encontrada na escrita dos dois tipos de morfemas possivelmente ocorria, porque no caso da morfologia derivacional, há uma mudança na classe gramatical das palavras morfologicamente complexas, o que não ocorre com a morfologia flexional. Assim, seria mais fácil para as crianças entender as relações morfêmicas nas flexões do que nas derivações.

No caso da morfologia derivacional, não há regras claras de como formar as palavras; no entanto, conhecer a relação entre a raiz e a palavra derivada pode ajudar o leitor a compreender o significado da palavra e saber como pronunciá-la, e ao escritor decidir sobre grafias ambíguas. Assim, a palavra "laranjeira" é escrita com “j” e não "g” porque vem da palavra "laranja", informação que o escritor pode utilizar. $\mathrm{O}$ leitor pode se beneficiar também, pois pode inferir que a palavra significa a "árvore que dá a laranja" (Luft, 1999).

Alguns autores argumentam que o processamento da morfologia derivacional começa tarde no desenvolvimento. No estudo de Deacon e Bryant (2005) as crianças estavam no início da alfabetização. Colé, Marec-Breton, Royer e Gombert (2003) estudaram a relação entre o processamento da morfologia derivacional e a escrita no francês. Os resultados de Colé et al. mostraram que desde os estágios iniciais da alfabetização a morfologia derivacional contribui para a leitura.

Uma outra característica dos morfemas que pode afetar o resultado de estudos que investigam o processamento morfológico diz respeito à relação fonológica entre os morfemas. Alguns morfemas têm relações fonologicamente transparentes "feliz" e "felizmente", e outros têm relações fonologicamente opacas "razão" e "racional". Pesquisas que observaram a relação entre o processamento de morfemas que tem relações fonológicas opacas e transparentes mostram que neste caso também as crianças reagem de forma diferente ao tipo de morfema. Fowler e Liberman (1995) demonstraram que tarefas que envolvem a relação opaca entre os morfemas correlacionam mais fortemente com a leitura do que aqueles com relações transparentes. A pesquisa de Fowler e Liberman permitiu levantar uma questão: uma vez que aspectos fonológicos influenciam o processamento dos morfemas, qual é o papel específico do processamento morfológico na alfabetização?

A argumentação principal para explicar a relação encontrada entre o processamento morfológico e a alfabetização no inglês diz respeito à natureza da ortografia inglesa. $\mathrm{O}$ princípio alfabético é o de que letras devem corresponder perfeitamente aos sons das palavras, mas as línguas alfabéticas variam quanto ao grau de correspondência entre as letras e os sons da fala. No inglês essas relações são mais opacas do que em ortografias como o português ou espanhol. Muitas das irregularidades encontradas no inglês podem ser explicadas pela estrutura morfológica das palavras (Chomsky \& Halle, 1968; Sterling, 1992). Por isso o processamento das palavras ao nível do morfema pode ajudar as crianças a ler e escrever.

No entanto, não é só no inglês que se tem observado um efeito facilitador da estrutura morfológica no desenvolvimento da leitura. No francês, no estudo já citado de Colé et al. (2003), demonstrou-se um efeito facilitador da consciência morfológica na leitura.

No português, uma série de estudos investigou a relação entre o processamento morfológico e a escrita. Mota (1996) mostrou que a partir da segunda série as crianças são capazes de utilizar regras gramaticais para decidir a grafia de palavras flexionadas. Mota, Moussatché, Castro, Moura e Ribeiro (2000) mostraram que adolescentes com baixa escolaridade processam os morfemas das palavras na escrita, e em um outro estudo Mota et al. (2002) observaram que as crianças de primeira série com os melhores escores nos testes de consciência morfológica eram também as crianças que escreviam melhor pseudopalavras com ortografia ambígua (ex., "muge"-"mugidor").

Meireles e Correa (2005) examinaram o desenvolvimento ortográfico em crianças no Ensino Fundamental. Crianças da $2^{\mathrm{a}}$ e $4^{\mathrm{a}}$ séries realizaram um ditado de palavras de baixa freqüência de ocorrência que incluía regras de natureza morfossintática (sufixos esa, oso e eza) e regras contextuais (usos do $r$ e $r r$ e da nasalização antes de consoantes). Os resultados mostraram que, como no estudo de Mota (1996), as crianças apresentam um desenvolvimento na aplicação de regras morfossintáticas na escrita.

Estudando a relação entre ortografia e morfo-sintaxe Rego e Buarque (1997) observaram que a consciência morfossintática das crianças contribuiu para o desempenho na escrita de palavras morfologicamente complexas.

Em um outro estudo que investigou a relação entre consciência morfossintática e desempenho ortográfico de crianças de $2^{\mathrm{a}}$ e $4^{\mathrm{a}}$ séries do ensino fundamental, Queiroga, Lins, e Pereira (2006) avaliaram a escrita das crianças através de ditados de palavras e pseudopalavras, e para avaliar a consciência morfossintática utilizaram uma tarefa de analogia gramatical. Os resultados deste estudo mostraram uma 
evolução entre as séries na escrita de palavras e pseudopalavras e na explicitação do conhecimento morfossintático. Encontrou-se também um efeito facilitador do conhecimento morfossintático para a escrita.

Embora estes resultados pareçam indicar que a consciência morfológica tem um papel importante no desenvolvimento da escrita no português, nos estudos citados, a influência do processamento fonológico raramente foi controlada. O papel da morfologia derivacional também não foi estudado especificamente. Nem a relação entre a consciência morfológica e a leitura. Como já argumentamos, a realização das tarefas de consciência morfológica pode ser afetada pelo conhecimento fonológico da língua. È possível que a relação encontrada entre consciência morfológica e escrita seja decorrente da consciência fonológica.

Nagy et al. (2006) descrevem dois modelos pelo qual a consciência morfológica pode contribuir para a leitura. O primeiro modelo proposto por Fowler e Liberman (1995) considera que a consciência morfológica contribui para leitura de forma secundária e deriva do conhecimento fonológico. Os autores argumentaram que pares de palavras que sofrem mudanças fonológicas (ex., "five"-"fith") exigem das crianças um nível de processamento fonológico maior do que os pares com relações transparentes (ex., "four"-"fourth"). Já que estes pares opacos têm as relações morfêmicas entre as palavras mascaradas pelas mudanças fonológicas, devem necessitar da aplicação de regras de correspondência entre letra e som para serem lidos ou escritos.

Nagy et al. (2006) discordam da interpretação de Fowler e Liberman (1995). Para Nagy et al. é possível que o fato da relação morfêmica entre as palavras ter sido mascarada torne esse um teste melhor de consciência morfológica e não um teste pior. Os autores continuam a sua argumentação lembrando que embora a consciência fonológica possa contribuir para a leitura e para escrita com uma parcela maior da variância do que a consciência morfológica, isto não significa que a contribuição da consciência morfológica não seja importante ou relevante.

O segundo modelo descrito por Nagy et al. (2006) é o proposto por Deacon e Kirby (2004), que defendem que a contribuição da consciência morfológica para a leitura é independente da consciência fonológica.

Para testar o seu modelo, Deacon e Kirby (2004) realizaram um estudo longitudinal de quatro anos. Neste estudo os autores mostraram que a consciência morfológica contribuiu para os escores de leitura em todas as tarefas apresentadas (leitura de palavras simples, pseudopalavras e compreensão da leitura), e esta contribuição foi independente da contribuição da consciência fonológica.

Nagy et al. (2006) delinearam um estudo para testar os dois modelos descritos acima. Os autores deram a crianças americanas de quarta série até a nona série (equivalente ao segundo ano do ensino médio no Brasil) tarefas de consciência morfológica, fonológica, leitura de palavras isoladas, compreensão de leitura, decodificação de palavras morfologicamente complexas e tarefa de escrita de pala- vras. Os resultados do estudo de Nagy et al. mostram que a contribuição da consciência morfológica foi independente da fonológica para todas as tarefas de processamento da leitura e escrita.

Os autores concluíram que o segundo modelo, que propõe que consciência morfológica contribui para leitura e escrita de forma independente da fonológica, é um modelo melhor para explicar o papel da consciência morfológica na escrita no inglês.

O português é uma língua com uma estrutura fonológica mais transparente do que o inglês e do que o francês. É possível formularmos a hipótese de que no português a contribuição da consciência morfológica não seja tão relevante para alfabetização quanto em outras línguas alfabéticas. No entanto, os poucos estudos feitos nesta área no português focaram na escrita, não controlaram o efeito da consciência fonológica (Mota, 1996; Mota et al., 2002) e se restringiram à grafia de palavras morfologicamente complexas (Rego \& Buarque, 1997; Queiroga et al., 2006). Este estudo foi delineado para controlar esses problemas. Crianças de primeira e segunda série realizaram tarefas de consciência morfológica, fonológica, leitura e escrita. A associação entre estas diversas variáveis foi testada.

\section{Método}

\section{Participantes}

Amostra do estudo constituiu de cinqüenta e uma crianças, sendo 27 alunas da $1^{\mathrm{a}}$ série e 24 da $2^{\mathrm{a}}$ série do ensino fundamental de uma escola pública, situada na região urbana de Juiz de Fora que atende a crianças de classe baixa e média. Dos 51 alunos, 30 eram meninas e 21 meninos. A média de idade das crianças de $1^{\mathrm{a}}$ série foi de 91.1 meses $(D P=4,8)$ e a da segunda série 103,9 meses $(D P=5,53)$. A participação do estudo dependeu do Termo de Consentimento Livre e Esclarecido. Três outras crianças não iniciaram o estudo (uma mudou de escola e as outras duas não quiseram participar da pesquisa). Todas as crianças matriculadas na $1^{\mathrm{a}}$ e $2^{\mathrm{a}}$ série do Ensino Fundamental foram convidadas a participar da pesquisa através de uma carta convite. A inclusão da criança no estudo dependeu da autorização do responsável através do Termo de Consentimento Livre e Esclarecido.

\section{Instrumentos}

\section{Tarefas de Consciência Morfológica}

Tarefa de Decisão Morfo-semântica (Besse, Vidigal de Paula \& Gombert, em comunicação pessoal, setembro, 2005). Nesta tarefa a criança tinha que decidir se uma palavra era construída da mesma forma que as outras. A explicação dada à criança era a seguinte: "em português há palavras que são da mesma família, como, por exemplo, "descobrir" e "cobrir", ou seja, "descobrir" vem de "cobrir". Acrescenta-se uma pequena coisa no início para fazer uma outra palavra. Outro exemplo é o caso de "desfazer" e "fazer", onde acrescenta o "des" no início de 
"fazer". Porém, há palavras que também se iniciam por “des", mas não vem de outra palavra como é o caso de "deslizar" que não vem de "lizar". Após a explicação fazia-se um exemplo com a criança: "qual a palavrinha que é feita da mesma maneira que "descobrir" é "deslizar" ou “desfazer?". Havendo a criança respondido corretamente, iniciava-se a tarefa; do contrário, dava-se a forma correta explicando a razão.

A lista de palavras consistia de 12 grupos de três palavras envolvendo prefixos e 12 grupos de palavra envolvendo sufixos (Anexo A).

Tarefas de Decisão Morfo-semântica - raiz (uma variação de Besse, Vidigal de Paula \& Gombert, em comunicação pessoal, setembro, 2005). A tarefa de Besse et al. (em comunicação pessoal, setembro, 2005) foi inicialmente delineada para crianças mais velhas do que as que participaram desse estudo. Com o objetivo de simplificar a tarefa original uma variação da mesma foi criada investigando o conhecimento da raiz das palavras. Utilizamos o termo variação e não adaptação, pois se tratou de uma modificação da tarefa e não uma adaptação da mesma para o contexto deste estudo. Nesta tarefa a criança tinha que decidir qual palavra era da mesma família que a palavra-alvo. Assim se explicava o seguinte: "algumas palavrinhas são da mesma família do que outras. Por exemplo, a palavra "conta" e a palavra "reconta" são da mesma família. Já a palavra "bola" e "rebola" não são da mesma família. Eu vou falar para você uma palavra e depois vou falar mais outras duas e você vai me dizer qual das duas é da mesma família da primeira". Por fim se fazia um exemplo junto com a criança: "a palavra "gela" é da mesma família que "congela" ou "conversa"?. Caso a criança errasse, explicava-se a forma correta, e se acertasse iniciava-se a tarefa.

As palavras foram pareadas pelo número de letras e a frequiência de ocorrência na escrita (Pinheiro, 1996; tabela para primeira série). Como não há índices de familiaridade para o português as palavras foram pareadas por frequiência para garantir minimamente um equilíbrio na familiaridade das palavras. A lista de palavras consistia de dez grupos de três palavras envolvendo prefixos e dez grupos de palavra envolvendo sufixos (Anexo A).

Tarefa de Associação Morfo-Semântica (Nagy et al., 2006). Nesta tarefa a criança tinha que decidir se duas palavras eram da mesma família ou de famílias diferentes. Assim, dava-se a explicação: "a palavra "bola" e a palavra "bolinha" são da mesma família. Já a palavra "bolo" e "bolinha" não". Depois um exemplo era feito junto com a criança: "a palavra bola é da mesma família que boleiro?". Respondendo de maneira exata, começava a atividade e caso a resposta estivesse incorreta, dizia-se a palavra correta e apresentava-se a explicação do exemplo (Anexo A). Dez pares de palavras foram criados, cinco pares pertenciam à mesma família e cinco eram de famílias diferentes. Todas as palavras partilhavam do mesmo som inicial, de maneira que diferenças no desempenho não poderiam ser atribuídas à semelhança fonológica, mas ao conhecimento da relação morfo-semântica das palavras.

Tarefa de Analogia Gramatical (adaptada de Nunes et al., 1997). Adaptamos a tarefa inicial de Nunes et al. para focar mais especificamente na morfologia derivacional do português. Nesta tarefa a criança tinha que produzir uma palavra morfologicamente complexa a partir de uma palavra-alvo, aplicando a mesma relação de derivação de um par previamente dado, como por exemplo: "pedra-pedreiro; leite- ?" e assim sucessivamente com os outros pares. Dez itens foram criados (Anexo A).

\section{Tarefas de Consciência Fonológica}

Foi usada a versão brasileira adaptada por CardosoMartins (1997) do oddity test de Bradley e Bryant (1983), investigando a categorização de rima e aliteração. Nesta tarefa a criança tem que decidir qual palavra não tem o mesmo som que outras em uma lista que lhe é apresentada (ex., "morcego", "panela" e "janela").

\section{Testes Padronizados}

Teste de Desempenho Escolar-TDE (Stein, 1994) - os itens de leitura de palavras isoladas e escrita do TDE foram aplicados para avaliar o desempenho na leitura e escrita das crianças. Utilizamos um teste padronizado por ser mais adequado para discriminar as diferenças individuais na leitura e escrita das crianças participantes deste estudo.

Escala de Inteligência Wechsler para crianças-WISC III (Wechsler, 1991) - os subtestes de Vocabulário, Compreensão e Dígitos foram aplicados. Os escores ponderados foram utilizados. Este teste foi aplicado para controlarmos a influência de variáveis ligadas ao desenvolvimento lingüístico na aquisição da leitura e escrita.

\section{Procedimento}

As crianças foram avaliadas individualmente em três sessões de 20 a 30 minutos. Na primeira foram realizados os testes de consciência morfológica e os testes de consciência fonológica. Na segunda sessão foram aplicados três subtestes do WISC (Vocabulário, Compreensão e Dígitos) e na última sessão foram aplicados os dois subtestes do Teste de Desempenho Escolar.

\section{Resultados}

A primeira pergunta que levantamos foi: há uma relação entre a consciência morfológica e o aprendizado da leitura e escrita em Português?

Para responder a essa pergunta, o número de respostas corretas nos testes foi computado, e correlações entre as diversas medidas foram tomadas. Para as tarefas de consciência metalingüística 1 ponto foi dado para cada resposta correta. A Tabela 1 mostra a média e o desvio padrão para o número de acertos em cada tarefa de consciência metalingüística por série. 
Tabela 1

Média e o Desvio Padrão (DP) para o Número de Respostas Corretas para cada Tarefa de Consciência Morfológica por Série

\begin{tabular}{|c|c|c|}
\hline Tarefa & $\begin{array}{c}1^{\mathrm{a}} \text { série } \\
\text { média }(D P)\end{array}$ & $\begin{array}{c}2^{\mathrm{a}} \text { Série } \\
\text { média }(D P)\end{array}$ \\
\hline Aliteração & $9,8(2,4)$ & $10,8(1,2)$ \\
\hline Rima & $9,4(2,2)$ & $10,5(1,9)$ \\
\hline Decisão Morfo-Semântica - raiz (prefixo) & $9,5(0,8)$ & $9,5(0,9)$ \\
\hline Decisão Morfo-Semãtica - raiz (sufixo) & $9,5(0,7)$ & $9,6(1,0)$ \\
\hline Decisão Morfo-Semântica (prefixo) & $6,5(1,5)$ & $7,0(1,4)$ \\
\hline Decisão Morfo-Semãtica (sufixo) & $5,9(1,2)$ & $6,0(2,4)$ \\
\hline Analogia Gramatical & $5,2(2,0)$ & $7,1(1,2)$ \\
\hline Tarefa de Associação Morfo-Semântica & $6,3(1,4)$ & $7,5(1,6)$ \\
\hline
\end{tabular}

A avaliação das repostas como corretas no teste de leitura e escrita seguiu os critérios do manual do TDE. Para as análises estatísticas foram utilizados os escores brutos, ou seja, o número de respostas corretas em cada subteste. Os dados coletados não foram adequados para realizar análises paramétricas. Assim, Correlações de Spearman foram empregadas. Os resultados mostraram uma correlação positiva e significativa entre três medidas de consciência morfológica e escrita: para Analogia Gramatical ( $r=0,58$; $p<0,01)$, para a tarefa de Decisão Morfo-semântica baseada na raiz e nos sufixos $(r=0,40 ; p<0,01)$ e para a tarefa de Decisão Morfo-semântica baseada na raiz e nos prefixos $(r=037 ; p<0,01)$. Nenhuma outra tarefa de consciência morfológica correlacionou de forma significativa estatisticamente com a escrita. A Tabela 2 mostra os resultados dessas correlações.

Tabela 2

Coeficiente de Correlação de Spearman

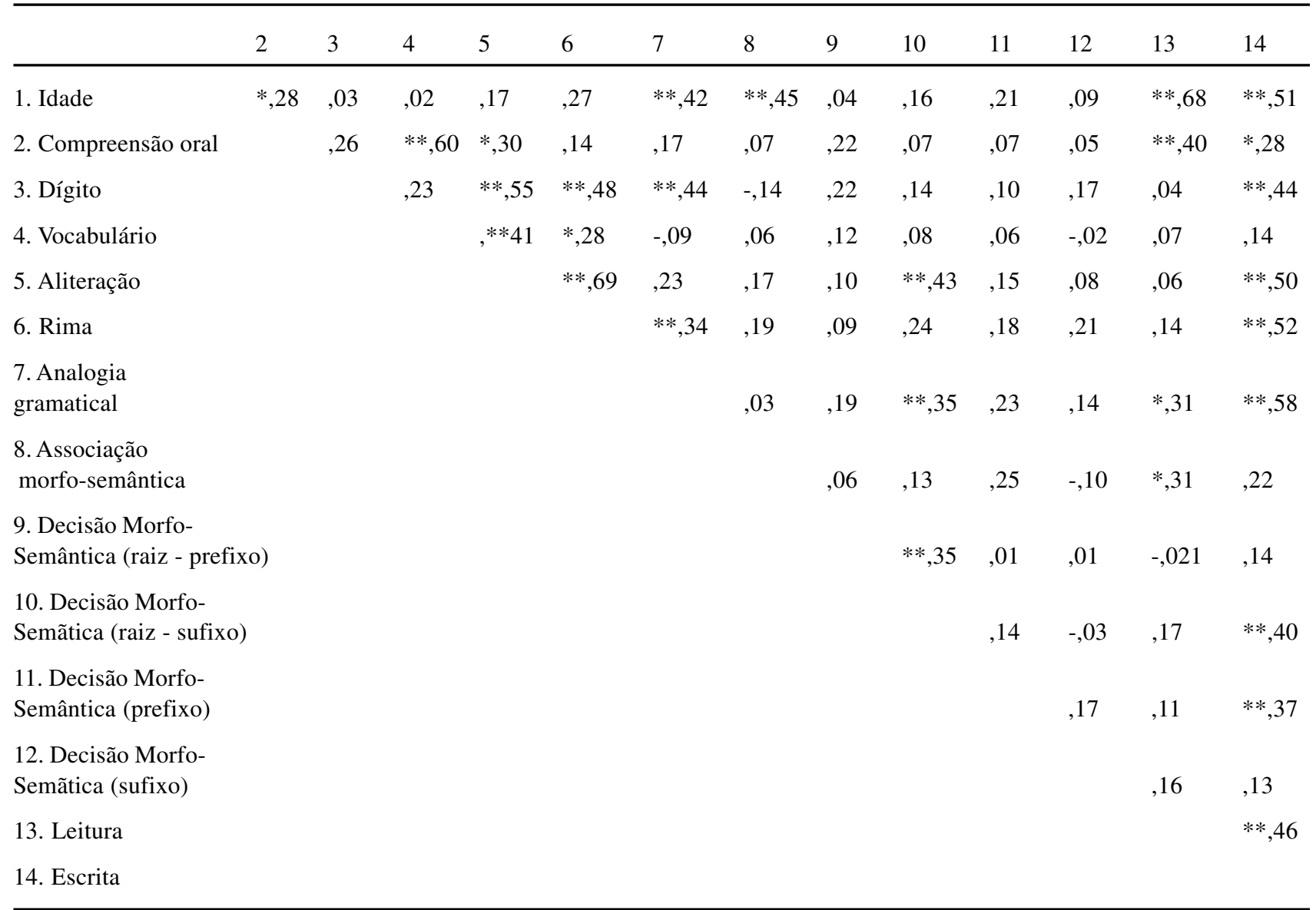

Notas. $* p<0,05 ; * * p<0,01$

Ambas as medidas de consciência fonológica correlacionaram de forma estatisticamente significativa e positiva com a tarefa de escrita $(r=0,50 ; p<0,01$; para a tarefa de aliteração e $r=0,52 ; p<0,01$ para a tarefa de rima).
Entretanto, estas tarefas não correlacionaram de forma significativa com a leitura (Tabela 2).

Uma outra medida de processamento fonológico é a medida de memória auditiva do WISC que correlacionou de 
forma significativa e positiva com as tarefas de escrita $(r=$ $0,44 ; p<0,01)$ e com a tarefa de analogia gramatical $(r=$ $0,44 ; p<0,01)$.

Quando correlações com medida de leitura foram executadas com as tarefas de Analogia Gramatical ( $r=0,30 ; p<$ $0,01)$ e a tarefa de Nagy $(r=0,31 ; p<0,01)$ estas produziram resultados significativos. Nenhuma outra tarefa de consciência morfológica produziu resultados estatisticamente significativos (ver Tabela 2).

A segunda pergunta feita foi: A contribuição da consciência morfológica para a leitura e escrita é independente da consciência fonológica?

As medidas de consciência fonológica (ver Tabela 1 para média e desvio padrão dessas medidas) correlacionaram significativamente e positivamente com a tarefa de escrita ( $r=0,50 ; p<0,01$ para a tarefa de aliteração, e $r=0,52 ; p<$ 0,01 para a tarefa de rima). Entretanto, não foram encontradas correlações estatisticamente significativas entre as tarefas de consciência fonológica e leitura (ver Tabela 2).

Como argumentamos anteriormente é possível que a contribuição da consciência morfológica para escrita no português não seja independente da consciência fonológica. Uma das tarefas de consciência morfológica, a de decisão morfo-semântica correlacionou de forma significativa e positiva com a escrita e com a tarefa de aliteração $(r=$ $0,43 ; p<0,01)$. A tarefa de analogia gramatical correlacionou de forma positiva e significativa com a tarefa de rima $(r=0,34 ; p<0,01)$ e com a escrita.

Uma análise de regressão múltipla com ordem fixa foi realizada para testar a contribuição da tarefa de decisão morfo-semântica baseada na raiz e nos sufixos, após a contribuição da consciência fonológica (aliteração) ter sido controlada. Os resultados mostraram que a tarefa morfosemântica baseada na raiz e nos sufixos não contribui de forma significativa $(\beta=0,08 ; t=4,7 ; p=0,4)$ para a escrita depois dos escores na tarefa de aliteração terem sido controlados.

Por outro lado, a análise de regressão que explorou a contribuição da tarefa de analogia gramatical para escrita depois da idade e dos escores na tarefa de rima serem controlados mostram que a analogia gramatical continua a contribuir para escrita após esses controles serem efetuados $(\beta=0,35 ; t=2,96 ; p=0,005)$.

Não houve correlações significativas entre a s medidas de consciência fonológica e os escores na leitura. Por isso, a regressão múltipla feita para avaliar a contribuição das tarefas de consciência morfológica e a leitura só controlou a idade. Os resultados mostram que a contribuição da tarefa de analogia gramatical é significativa depois destes controles efetuados $(\beta=0,21 ; t=2,23 ; p=0,03)$, mas a tarefa adaptada de associação morfo-semântica de Nagy et al. (2006), que havia correlacionado de forma significativa e positiva com a leitura, não se manteve significativa após o controle da idade $(\beta=0,08 ; t=0,09 ; p=0,4)$.

\section{Discussão}

A primeira pergunta que fizemos foi: a consciência morfológica contribui para a leitura e escrita em português? Os resultados deste estudo mostram que três das medidas de consciência morfológica correlacionaram de forma positiva e significativa com a escrita. A tarefa de decisão morfo-semântica envolvendo a raiz e sufixos, a tarefa de decisão morfo-semântica de Besse et al. (em comunicação pessoal, setembro, 2005) envolvendo o prefixo e a tarefa de analogia gramatical. Estes resultados sugerem que as crianças que melhor processam os aspectos morfológicos da língua melhor se saem na escrita.

Na leitura, as tarefas adaptadas de associação morfo-semântica de Nagy et al. (2006) e a tarefa de analogia gramatical se correlacionaram de forma positiva e significativa com os escores do TDE, indicando uma associação entre o processamento morfológico e a leitura no português. Estes resultados são consistentes com os obtidos nos estudos realizados em língua inglesa (Carlisle, 1988, 1995, 1996, 2000; Carlisle \& Fleming, 2003; Deacon \& Kirby, 2004; Nagy et al., 2006; Nunes et al., 1997), e chamam atenção da necessidade de se investigar mais profundamente o papel dessa habilidade metalingüística no desempenho da leitura e escrita no português.

O português é uma língua com correspondências entre letra e som bem regulares, porém com estrutura morfológica complexa. Um aspecto metodológico importante é estabelecer, como sugerem Deacon e Kirby (2004), se a consciência morfológica apresenta uma contribuição específica para leitura e escrita, independente de outras habilidades metalingüísticas, especialmente a consciência fonológica.

Nesse estudo, as duas tarefas que se correlacionaram de forma significativa com a leitura foram as tarefas menos influenciadas pelo processamento fonológico e nenhuma das tarefas de consciência fonológica correlacionou de forma estatisticamente significativa com a leitura.

A literatura na área de consciência fonológica mostra a associação entre as tarefas de consciência fonológica e a aprendizagem da língua escrita no português (Barrera \& Maluf, 2003; Capovilla \& Capovilla, 2000). Nunes et al. (1997) mostram uma evolução na escrita de crianças inglesas, que partem do princípio alfabético para chegar à aplicação de regras ortográficas mais complexas na escrita. No português resultados semelhantes foram encontrados (Meireles \& Correa, 2005; Mota, 1996). Pode se levantar a hipótese de que as crianças neste estudo já tenham aprendido as regras de correspondência letra e som no português, e estejam numa etapa de seu desenvolvimento que requeira a atenção para aspectos complexos da ortografia, que exijam o processamento da morfologia. Entretanto, esta questão precisa ser mais bem investigada.

Este resultado levanta a questão de que a consciência morfológica e a fonológica podem contribuir de forma diferente para a leitura e escrita no português. Nation e Hulme (1997) lembram que na leitura todas as pistas gráficas estão presentes, enquanto na escrita, as crianças têm que 
representar o som das palavras com pouca ou nenhuma ajuda do contexto e destas pistas. Assim, é possível que o processamento fonológico seja mais importante na escrita do que o processamento sintático-semântico (Rego \& Bryant, 1993).

Tarefas como as de decisão morfo-semântica que envolvem a raiz dos morfemas, apresentam relações fonológicas transparentes entre a raiz e a palavra derivada. É possível que o conhecimento das crianças neste tipo de tarefa esteja associado à consciência fonológica e não à consciência morfológica. De fato, todas as três tarefas de processamento fonológico estavam associadas ao bom desempenho na escrita e não a leitura. Embora possa ser argumentado que a relação fonológica transparente ajude na identificação da relação morfêmica (Carlisle, Stone \& Katz, 2001) é preciso separar essas duas variáveis.

Para testar a hipótese de que a contribuição da consciência morfológica é mediada pela consciência fonológica na escrita, regressões logísticas foram realizadas nas tarefas que concomitantemente correlacionaram com a escrita e a consciência fonológica. A tarefa de analogia gramatical contribuiu para a escrita mesmo depois de controlarmos os efeitos da idade e do processamento fonológico e para a leitura depois de controlarmos a idade.

Estes resultados dão suporte ao modelo proposto por Deacon e Kirby (2004), de que há uma contribuição independente da consciência morfológica para a alfabetização, e a hipótese levantada de que essa contribuição ocorre também em línguas alfabéticas como o português.

No que diz respeito ao papel específico da morfologia derivacional, estes resultados precisam ser tomados com cautela. Alguns itens da tarefa de analogia gramatical envolveram mudanças na classe gramatical das palavras. Embora, tenham sido apenas dois, precisamos investigar se essa tarefa envolveu o processamento morfossintático também. Deacon e Bryant (2005) mostraram que crianças pequenas processam esse tipo de par de palavras melhor do que pares de palavras derivadas. Estudos com controles para o processamento fonológico e o tipo de morfema precisam ser realizados para confirmar nossos resultados.

Assim, de um modo geral, os resultados obtidos sugerem que, a morfologia derivacional contribui de forma independente da consciência fonológica para a leitura e escrita no português. Contudo, para se estabelecer uma possível conexão causal entre essa habilidade metalingüística e a alfabetização estudos longitudinais que combinem técnicas correlacionais são necessários. Mais estudos são necessários também para explorar o desenvolvimento dessa habilidade metalingüística em crianças brasileiras e o efeito que o ensino dessa habilidade pode ter no desempenho escolar.

\section{Referências}

Barrera, S., \& Maluf, M. R. (2003). Consciência metalingüística e alfabetização: Um estudo com crianças da primeira série do ensino fundamental. Psicologia: Reflexão e Crítica, 16(3), 491502.
Bradley, L., \& Bryant, P. (1983). Categorizing sounds and learning to read: A causal connection. Nature, 301, 419-421.

Capovilla, A., \& Capovilla, F. (2000). Efeitos do treino de consciência fonológica em crianças com baixo nível sócio-econômico. Psicologia: Reflexão e Crítica, 13(1), 07-24.

Cardoso-Martins, C. (1997). A sensibilidade e rima e ao fonema e a aquisição da leitura em crianças normais e indivíduos com a síndrome de Down: Um estudo correlacional. Tese para obtenção de título de professor titular, não-publicada, Universidade Federal de Minas Gerais, Belo Horizonte, MG.

Carlisle, J. (1988). Knowledge of derivational morphology and spelling ability in fourth, six, and eight graders. Applied Psycholinguistics, 9, 247-266.

Carlisle, J. (1995). Morphological awareness and early reading achievement. In L. Feldman (Ed.), Morphological aspects of language processing (pp. 189-211). Hillsdale, NJ: Lawrence Erlbaum.

Carlisle, J. (1996). An exploratory study of morphological errors in children's written stories. Reading and Writing: An Interdisciplinary Journal, 8, 61-72.

Carlisle, J. (2000). Awareness of the structure and meaning of morphologically complex words: Impact on reading. Reading and Writing: An Interdisciplinary Journal, 12, 169-190.

Carlisle, J., \& Fleming, J. (2003). Lexical processing of morphologically complex words in the elementary years. Scientific Studies of Reading, 7(3), 239-253.

Carlisle, J., Stone, C., \& Katz, L. (2001). The effects of phonological transparency on reading derived words. Annals of Dyslexia, 51, 249-274.

Chomsky, N., \& Halle, M. (1968). The sound patterns of English. New York: Harper \& Row.

Colé, P., Marec-Breton, N., Royer, C., \& Gombert, J. E. (2003). Morphologie des mots et apprentissage de la lecture. Reeducation Orthophonic, 213, 57-60.

Deacon, S., \& Bryant, P. (2005). What young children do and do not know about the spelling of inflections and derivations. Developmental Science, 8(6), 583-594.

Deacon, S., \& Kirby, J. (2004). Morphological awareness: Just "more phonological"? The roles of morphological and phonological awareness in reading development. Applied Psycholinguistics, 25, 223-238.

Fowler, A., \& Liberman, I. (1995). The role of phonology and orthography in morphological awareness. In L., Feldman (Ed.), Morphological aspects of language processing (pp. 157-188). Hillsdale, NJ: Lawrence Erlbaum.

Laroca, M. (2005). Manual de morfologia do português. Campinas, SP: Pontes.

Luft, C. (1999). Minidicionário Luft. São Paulo, SP: Ática.

Marec-Breton, N., \& Gombert, J. (2004). A dimensão morfológica nos principais modelos de aprendizagem da leitura. In M. R. Maluf (Ed.), Psicologia educacional: Questões contemporâneas (pp. 105-122). São Paulo, SP: Casa do Psicólogo.

Meireles, E., \& Correa, J. (2005). Regras contextuais e morfossintáticas na aquisição da ortografia da língua portuguesa por criança. Psicologia: Teoria e Pesquisa, 21(1), 77- 84.

Mota, M. (1996). Children's role of grammatical rules in spelling. Unpublished doctoral dissertation, Department of Experimental Psychology, University of Oxford, England.

Mota, M., Andrade, C., Henrique, D, Macedo, S., Atalaia, K., Stephan, F., \& Ferreira, D. (2002). Consciência sintática e desenvolvimento ortográfico. In Anais do IV Seminário de Psicopedagogia da Universidade do Estado do Rio de Janeiro: Vol. 1. Encontros Psicopedagógicos (pp. 35-39). Rio de Janeiro, RJ: Editora da Universidade do Estado do Rio de Janeiro. 
Mota, M., Moussatché, A. H., Castro, C., Moura, M. L. S., \& Ribeiro, T. (2000). Erros de escrita no contexto: Uma análise dentro da abordagem da teoria do processamento da informação. Psicologia: Reflexão e Crítica, 13(1), 1-6.

Nagy, W., Berninger, V., \& Abbot, R. (2006). Contributions of morphology beyond phonology to literacy outcome of upper elementary and middle-school students. Journal of Educational Psychology, 98(1), 134-147.

Nation, K., \& Hulme, C. (1997). Phonemic segmentation, not onset-rime segmentation, predicts early reading and spelling skills. Reading Research Quarterly, 32(2), 154-167.

Nunes, T., Bindman, M., \& Bryant, P. (1997). Morphological strategies: Developmental stages and processes. Developmental Psychology, 33(4), 637-649.

Pinheiro, A. M. V. (1996). Contagem de freqüência de ocorrência de palavras expostas a crianças na faixa pré-escolar e séries iniciais do $1^{o}$ grau [Software para computador]. São Paulo, SP: Associação Brasileira de Dislexia.
Rego, L., \& Bryant, P. (1993). The connections between phonological, syntactic and semantic skills and children's reading and spelling. European Journal of Psychology, 3, 235-246.

Rego, L., \& Buarque, L. (1997). Consciência sintática, consciência fonológica e aquisição de regras ortográficas. Psicologia: Reflexão e Crítica, 10(2), 199-217.

Queiroga, B., Lins, M., \& Pereira, M. (2006). Conhecimento morfossintático e ortografia em crianças do ensino fundamental. Psicologia: Teoria e Pesquisa, 22(1), 95-99.

Stein, L. M. (1994). TDE - Teste de desempenho escolar: Manual para aplicação e interpretação. São Paulo, SP: Casa do Psicólogo.

Sterling, C. (1992). Introduction to the psychology of spelling. In C. Sterling \& C. Robson (Eds.), Psychology, spelling \& Education (pp. 1-15). Adelaide, Austrália: Multilingual Matters.

Wechsler, D. (1991). WISC-III: Escala de inteligência Weschsler para crianças. São Paulo, SP: Casa do Psicólogo.

\section{ANEXO}

\section{Tarefas de Consciência Morfológica}

1. Decisão morfo-semântica (Besse, Vidigal de Paula \& Gombert, em comunicação pessoal, setembro, 2005)

Prefixo: Base-simples-derivada

Descolorir-Deslizar-Destorcer; Desanimar-Despedir-Desobedecer; Desabafar-Destinar-Desatar; Desarmar-DespertarDesconfiar; Desconhecer-Desafiar-Desrespeitar; Desatar-Desperdiçar-Descuidar; Reflorir-Recomendar-Reconhecer; Reaparecer-Recuperar-Reproduzir; Revender-Relatar-Reformar; Reabrir-Regar-Reler; Reescrever-Relacionar-Reflorestar; Replantar-Reservar-Relembrar

\section{Sufixo: Base-Simples-Derivada}

Chaveiro-Pandeiro-Cinzeiro; Galinheiro-Chiqueiro-Formigueiro; Passageiro-Escoteiro-Açougueiro; JardineiroPioneiro-Guerreiro; Letreiro-Cheiro-Faqueiro; Bagageiro-Picadeiro-Banheiro; Corredor-Computador-Regador; Protetor-Autor-Inventor; Fedor-Furor-Frescor; Sucessor-Doutor-Pintor; Instrutor-Major-Feitor; Amargor-Vigor-Temor

2. Tarefa de decisão morfo-semântica - raiz

Prefixo: Base-Derivada (en, re, des)- Simples

Canta-Encantada-Enfeitada; Gole-Engole-Enxerga ; Rola-Enrola -Enxuga ; Cera-Encera-Encosta; Ler-Releia -Relata; Tirar-Retira -Reserva ; Tornar-Retorna -Resolve ; Aguar-Deságua -Deserta; Cansar-Descanso-Desmaio ; Cobrir-Descobre -Desperta

Sufixo: Base-Derivada (eiro,or, ada)-Simples

Pinho-Pandeiro-Pinheiro; Leite-Ligeira-Leiteira; Banho-Fevereiro-Banheiro; Canta-Motor-Cantor; Pinta-Tambor-Pintor; Ler-Doutor-Leitor; Vale-Calor-Valor; Faca-Espada-Facada; Laço-Jangada-Laçada; Chave-Chiqueiro-Chaveiro

3. Tarefa de Associação Morfo-Semântica (Nagy et al., 2006).

Pares relacionados: chique-chiqueiro, panda-pandeiro, banda-bandeira, figa-fígado, calo calor

Pares não relacionados: pedra-pedreiro, banho-banheiro, pinho-pinheiro, liga-ligado, escrita-escritor

4. Analogia Gramatical (adaptado de Nunes et al., 1997)

(a) pedra-pedreiro; leite-? (b) leitor-leu; escritor-? (c) banana-bananada; goiaba-? (d) pintor-pintura; livreiro-?

(e) livro-livraria; pão-? (f) goma-engoma; gole-? (g) tênis-tenista; arte-? (h) lixo-lixeira; faca-?

(i) duque-duquesa; rei-? (j) claro-clareza; belo-? 